\title{
Characteristics of paediatric patients with tuberculosis and associated determinants of treatment success in Malaysia using the MyTB version 2.1 database over five years
}

S. Maria Awaluddin ${ }^{1,2}$, Nurhuda Ismail ${ }^{1 *}$ (D), Yuslina Zakaria ${ }^{3}$, Siti Munira Yasin ${ }^{1}$, Asmah Razali ${ }^{4}$, Mohd Hatta Abdul Mutalip², Noor Aliza Lodz ${ }^{2}$, Kamarul Imran Musa ${ }^{5}$, Faridah Kusnin ${ }^{6}$ and Tahir Aris $^{7}$

\begin{abstract}
Background: Tuberculosis (TB) among children remains a significant public health problem in many parts of the world. The objective of this study was to describe the characteristics of TB patients and to determine the predictors of treatment success among children in Malaysia.

Methods: Secondary data from MyTB version 2.1, a national database, were analysed using R version 3.6.1. Descriptive analysis and multivariable logistic regression were conducted to identify treatment success and its determinants.

Results: In total, 3630 cases of TB cases were registered among children in Malaysia between 2013 and 2017. The overall treatment success rate was 87.1\% in 2013 and plateaued between 90.1 and 91.4\% from 2014 to 2017. TB treatment success was positively associated with being a Malaysian citizen $(a \mathrm{O}=3.43 ; 95 \% \mathrm{Cl}=2.47,4.75)$, being a child with $\mathrm{BCG}$ scars $(\mathrm{aOR}=1.93 ; 95 \% \mathrm{Cl}=1.39,2.68)$, and being in the older age group ( $\mathrm{aOR}=1.06 ; 95 \% \mathrm{Cl}=1.03$, 1.09). Having HIV co-infection ( $\mathrm{aOR}=0.31 ; 95 \% \mathrm{Cl}=0.16,0.63)$, undergoing treatment in public hospitals $(\mathrm{aOR}=0.38$; $95 \% \mathrm{Cl}=0.25,0.58)$, having chest $\mathrm{X}$-ray findings of advanced lesion $(\mathrm{aOR}=0.48 ; 95 \% \mathrm{Cl}=0.33,0.69)$, having EPTB $(\mathrm{aOR}=0.58 ; 95 \% \mathrm{Cl}=0.41,0.82)$ and having sputum-positive PTB $(\mathrm{aOR}=0.58 ; 95 \% \mathrm{Cl}=0.43,0.79)$ were negatively associated with TB treatment success among children.

Conclusions: The overall success rate of treatment among children with TB in Malaysia has achieved the target of 90\% since 2014 and remained plateaued until 2017. The socio-demographic characteristics of children, place of treatment, and TB disease profile were associated with the likelihood of TB treatment success among children. The treatment success rate can be increased by strengthening contact tracing activities and promoting early identification targeting the youngest children and non-Malaysian children.
\end{abstract}

Keywords: Tuberculosis, Paediatric, Children, Malaysia, Treatment success

\footnotetext{
* Correspondence: nurhuda169@gmail.com

'Department of Public Health Medicine, Faculty of Medicine, Universiti

Teknologi MARA, Sungai Buloh Campus, Jalan Hospital, 47000 Sungai Buloh, Selangor, Malaysia

Full list of author information is available at the end of the article
}

C C The Author(s). 2020 Open Access This article is licensed under a Creative Commons Attribution 4.0 International License, which permits use, sharing, adaptation, distribution and reproduction in any medium or format, as long as you give appropriate credit to the original author(s) and the source, provide a link to the Creative Commons licence, and indicate if changes were made. The images or other third party material in this article are included in the article's Creative Commons licence, unless indicated otherwise in a credit line to the material. If material is not included in the article's Creative Commons licence and your intended use is not permitted by statutory regulation or exceeds the permitted use, you will need to obtain permission directly from the copyright holder. To view a copy of this licence, visit http://creativecommons.org/licenses/by/4.0/ The Creative Commons Public Domain Dedication waiver (http://creativecommons.org/publicdomain/zero/1.0/) applies to the data made available in this article, unless otherwise stated in a credit line to the data. 


\section{Background}

Tuberculosis (TB) disease affects children aged 0 to 14 years due to recent Mycobacterium tuberculosis (mtb) infection $[1,2]$. TB among children reflects the ongoing TB trasmission in the community, which needs public health attention [3]. Globally, children with TB accounted for $11 \%$ of the total TB cases in 2018 [4]. In Malaysia, children had approximately 3\% of the total TB cases for the 2010-2015 Malaysian cohort [5]. In terms of TB burden, Malaysia was considered to have an intermediate TB burden with an estimated incidence rate of 92 cases per 100,000 people in 2018 [6]. Countries neighbouring Malaysia, such as the Philippines, Indonesia, Myanmar and Thailand, are among the countries with a high TB burden [4].

A study of the global estimation of TB burden among children revealed that 239,000 patients died in 2015 , of whom $80 \%$ were under 5 years old, and more than $96 \%$ did not receive any prior TB treatment [7]. Data on TB among children are missing from the global surveillance database due to the nonspecific clinical presentations and lack of sputum samples, which lead to underreporting and undertreatment [2]. Thus, TB among children remains a significant public health problem in many countries, including Malaysia.

TB disease is curable and preventable; therefore, the treatment success rate is an indicator of the national TB control programme (NTP) worldwide. The global success rate is set at $90 \%$ by the World Health Organization (WHO) [8]. Treatment success rates among children have ranged from 63.5 to $92.4 \%$ because hospital-based data may yield lower treatment success rates than the NTP database $[9,10]$. Studies conducted among certain countries with a high TB burden reported treatment success rates above the WHO target, such as $92.4 \%$ in Pakistan and $91.7 \%$ in Iran $[9,11]$. However, studies conducted in African countries indicated treatment success rates below 90\% [12-14]. Treatment success in countries with a low TB burden are nearly $100 \%[15,16]$. Treatment success in Malaysia just achieved the WHO target of $90 \%$ but did not meet the local goal of 95\% in 2020 [5].

TB treatment success among children has been associated with several determinants, such as age, sex, place of residence, citizenship, type of TB disease, HIV coinfection, nutritional status, and exposure to cigarette smoke $[9,11,12,14]$. Danggiso et al. found that children aged 10-14 years have a higher treatment success rate and those aged 0-4 years have a lower treatment success rate than children aged 5-9years [12]. A study conducted in Pakistan found that children who were PTB positive lived in rural residences and that younger age groups were more likely to have unsuccessful treatment [9].
TB cases among children in Malaysia differ from those reported in countries with a high $\mathrm{TB}$ burden in the African region, as Malaysia has a low prevalence of HIV co-infection and multidrug-resistant (MDR) TB. Furthermore, healthcare services and policies regarding TB disease in Malaysia also differ from those in neighbouring countries, such as Indonesia and the Philippines, in terms of BCG vaccination coverage and treatment cost. Therefore, utilizing surveillance data is cost-beneficial for monitoring the success of TB control programmes in general. Various studies have used secondary data to seek the determinants of treatment outcomes, focusing either on treatment success or on unsuccessful treatment $[9,12,14]$. The first objective of the current study was to describe the characteristics of TB patients and to determine the rate of treatment success according to the socio-demographic profiles of children in Malaysia. The second objective was to determine the predictors of treatment success among children with TB in Malaysia.

\section{Methods \\ Data and sampling}

The study utilized a cross-sectional study design to analyse secondary data from MyTB version 2.1, a national TB surveillance database. It has used an online data entry system since 2011 and contains all TB case registrations for each year. The online system has enabled designated health staff in each district of the 13 states and three federal territories in Malaysia to register TB cases and related information, including sociodemographic profiles, TB investigations, TB diagnosis, medication and treatment outcomes. The data were monitored by the TB sector at the state level and finally at the national level. The MyTB version 2.1 manual adopted the previous version of the Tuberculosis Information System (TBIS), which used hardcopy documentation. Standard definitions were used for each variable in MyTB version 2.1. Certain variables still had higher rates of missing data, such as household income, education level and the number of household dependents. There were no variables to assess the socio-economic status of the parents of children with $\mathrm{TB}$ in this database. For this study, the analysis was conducted with data from 2013 to 2017. An optimal sample size of 2911 cases was needed to obtain statistically meaningful findings. The total number of registered TB cases among children was 3630 for 2013-2017.

\section{Variables definition}

Treatment outcome was defined according to the WHO guidelines, "Definitions and reporting framework for tuberculosis-2013 revision". Treatment outcomes consisted of six categories: cured, completed, failed, death, lost to follow-up and not evaluated. These categories 
can further be classified into two groups, treatment success and unsuccessful treatment. A child who has completed treatment and shows evidence of being cured as reflected in sputum status is considered cured. A child who has completed treatment but has no confirmed sputum result is categorized as completed because he/she might have sputum-negative PTB or EPTB. The unsuccessful treatment group comprised children who failed treatment, those who died, those lost to follow-up and those who were not evaluated [17].

The independent variables were socio-demographic variables such as age, sex, citizenship and ethnicity. Malaysia is a multi-ethnic country, with the major ethnicities being Malay, Chinese and Indian. Other ethnicities included Bumiputera Sabah and Bumiputera Sarawak. In this study, "Others" refer to Malaysian citizens whose ethnicities are not mentioned above. Rural and urban residents were categorized based on the definition from the Department of Statistics Malaysia. Localities were classified as urban areas if they were under city council management and had a population of 10,000 and above [18]. TB disease profiles included variables such as TB disease diagnosis, sputum result, chest X-ray findings and HIV co-infection status.

\section{Data analysis}

Data were analysed using $\mathrm{R}$ for Windows, Version 3.6.1 [19]. The Summary Tools package [20] was used to conduct a descriptive analysis by tabulating the frequency table and contingency table with the chi-square test results. The generalized linear model (GLM) family logit function under the CAR package [21] was used to measure the odds ratios in simple and multivariable logistic regression tests. For model fit assessment, the Resource Selection package [22] was utilized to calculate the Hosmer-Lemeshow goodness of fit. Simple logistic regression was conducted to assess the association between the individual independent variables and the dependent variable. All the independent variables were included in the final model based on a $p$-value less than 0.25 [23], based on clinically relevant and supporting evidence from the literature review. The preliminary main effect model included eleven independent variables in the analysis, and two independent variables were excluded from the final main effect model due to significant interaction terms. Model fit and regression diagnostics were assessed to ensure a robust model. Finally, the MICE package was used to perform a multiple imputation model [24] because the main effect model was analysed only for 3132 out of 3550 cases. Multiple imputations via the chained equation method were conducted on a variable-by-variable basis for each incomplete pair of tested variables. The results for the adjusted odds ratios (aORs) were reported based on the multiple imputation model.

\section{Results}

This study analysed data from a total of 3630 registered TB cases among children in Malaysia from 2013 to 2017. However, the final analysis included only 3550 cases because the other cases had missing data on treatment outcomes or because the final diagnosis changed to something other than TB. Table 1 illustrates the trends of $\mathrm{TB}$ case registration and treatment success among children from 2013 to 2017. The overall rate of treatment success among children with TB in Malaysia was $90.1 \%$.

Table 2 shows the results of descriptive analysis of the registered TB cases among children in Malaysia. In terms of ethnicity, $42.5 \%$ of the TB patients among children in Malaysia were Malays, followed by $19.8 \%$ Bumiputera Sabah, 10.7\% Bumiputera Sarawak, 13.5\% NonMalaysian, 5.4\% Chinese, 4.4\% Others, and 3.6\% Indian. The highest proportion of TB cases was among children aged 10-14 years, followed by children aged $0-4$ years and those aged 5-9 years (43.5, 37.0 and $19.5 \%$, respectively). Of the $479 \mathrm{~TB}$ cases among non-Malaysian children, the highest proportion was from the Philippines, followed by Indonesia and Myanmar (55.5, 24.6 and $16.1 \%$, respectively). A total of $94.3 \%$ (2897/3701) of Malaysian citizens had BCG scars, whereas only 36.5\% (175/479) of non-Malaysian citizens had BCG scars.

Table 3 shows the rates of TB treatment success according to the socio-demographic and TB disease profiles. The percentage of $\mathrm{TB}$ treatment success was significantly higher among older children and children who were Malaysian citizens. Having TB detected through active findings, having chest $\mathrm{X}$-ray findings of no or minimal lesion, not having human immunodeficiency virus (HIV) co-infection and having sputumnegative PTB were also associated with higher treatment success rates. Children who underwent treatment in a public clinic or private facility had higher treatment success than those treated in a public hospital.

Table 4 shows the results of simple logistic regression and multivariable logistic regression to determine the predictors of TB treatment success among children with TB in Malaysia. TB treatment success was positively associated with being a Malaysian citizen $(\mathrm{aOR}=3.43$; $95 \%$ $\mathrm{CI}=2.47,4.75)$, have $\mathrm{BCG}$ scars $(\mathrm{aOR}=1.93 ; 95 \% \mathrm{CI}=$ $1.39,2.68)$, and being in the older age group $(\mathrm{aOR}=$ 1.06; $95 \% \mathrm{CI}=1.03,1.09$. Having HIV co-infection $(\mathrm{aOR}=0.31 ; 95 \% \mathrm{CI}=0.16,0.63)$, receiving treatment in public hospitals $(\mathrm{aOR}=0.38$; 95\% $\mathrm{CI}=0.25,0.58)$ having chest X-ray findings of advanced lesion $(\mathrm{aOR}=0.48 ; 95 \%$ $\mathrm{CI}=0.33$, 0.69), having EPTB $(\mathrm{aOR}=0.58 ; 95 \% \mathrm{CI}=0.41$, $0.82)$ and having sputum-positive PTB (aOR $=0.58$; $95 \%$ 
Table 1 Data on TB cases registration in MyTB version 2.1 and TB treatment success among children in Malaysia, 2013-2017

\begin{tabular}{|c|c|c|c|c|c|c|c|c|c|c|}
\hline \multirow[t]{2}{*}{ Years } & \multicolumn{5}{|c|}{ Number of registered cases in MyTB version 2.1} & \multirow{2}{*}{$\begin{array}{l}\text { The } \\
\text { proportion } \\
\text { of } \\
\text { paediatric } \\
\text { cases } \\
(\%)\end{array}$} & \multicolumn{4}{|c|}{ Treatment outcome according to age groups (\%), $n=3550$} \\
\hline & All cases & $0-4$ years & $5-9$ years & $10-14$ years & $0-14$ years & & $0-4$ years & $5-9$ years & $10-14$ years & $0-14$ years \\
\hline 2013 & 24,069 & 279 & 144 & 314 & 737 & 3.1 & 79.0 & 93.0 & 91.2 & 87.1 \\
\hline 2014 & 24,701 & 244 & 141 & 315 & 700 & 2.8 & 87.6 & 89.9 & 92.9 & 90.4 \\
\hline 2015 & 24,160 & 275 & 142 & 328 & 745 & 3.1 & 88.5 & 92.9 & 93.2 & 91.4 \\
\hline 2016 & 25,736 & 255 & 144 & 311 & 710 & 2.8 & 88.7 & 92.0 & 93.1 & 91.3 \\
\hline 2017 & 26,159 & 300 & 136 & 302 & 738 & 2.8 & 87.1 & 92.5 & 91.9 & 90.1 \\
\hline
\end{tabular}

$\mathrm{CI}=0.43,0.79)$ were negatively associated with TB treatment success among children.

\section{Discussion}

This study describes the characteristics of children with TB in Malaysia from 2013 to 2017 using the recommended NTP surveillance database. TB incidence among children is monitored according to age group, as younger children constitute a high-risk group for TB disease complications [25]. The standard age disaggregation for WHO TB reporting among children is as follows: 0-4 years and 5-14 years [2]. Other researchers have divided age groups into three categories: 0-4 years, 5-9 years, and 10-14 years [12, 14]. A few studies in countries with a low TB burden have used different cut-off points to define paediatric $\mathrm{TB}$, such as being under 18 years $[16,26]$ or $0-16$ years [15]; in such cases, inter-country comparison was unsuitable.

The proportion of registered TB cases among children in Malaysia was less than $5 \%$ compared to the total registered cases. The ratio of $\mathrm{TB}$ cases was much lower among the age group 0-4 years than among the older group. Regarding these findings, the national database is still far from the WHO benchmarks for a higher-quality database for children with TB disease [27]. The most cases were in children aged 10-14 years, followed by those aged $0-4$ years. In particular, the youngest age group has a 30 to $40 \%$ risk of developing PTB disease and a 10 to $20 \%$ of developing TB meningitis or miliary TB following Mtb infection. The risk of PTB disease was $2 \%$ for children aged 5-9 years and between 10 and 20\% for those aged 10-14 years [28]. Younger children have immature immune systems, while adolescents have greater social contact, leading to a greater risk of TB infection [29]. The number of registered TB cases was low for children aged 0-4 years because there were more missing cases, even though Malaysia does not have a high TB burden. A known challenge for cases among children is accurately diagnosing TB because of the nonspecific symptoms and paucibacillary. A study conducted among countries with a high TB burden found a low number of cases among the 0-4-year age group compared to the older age group, which indicates the possibility of missing cases among the younger age groups $[11,12,30]$.

The proportion of registered TB cases among children in Malaysia can be broken down by the main ethnicities in Malaysia, including non-Malaysian citizens, who accounted for $13.5 \%$ of cases. Among immigrants, a higher proportion of TB patients originated from neighbouring countries such as the Philippines, Indonesia and Myanmar, countries with a high TB burden [4]. Similar observations have been made among registered TB cases in countries with a low TB burden, such as Israel, Australia and Canada, where a substantial proportion of TB cases were immigrants from countries with a high TB burden [15, 16, 31].

The overall rate of treatment success among children in Malaysia was $90.1 \%$, which achieved the WHO target of $90 \%$, except for children under 5 years old. The Malaysian goal of a 95\% treatment success rate in 2020 seems unachievable [5]. The rates of treatment success in other countries varied because of the wide range of data source used, either from an NTP database or review of hospital-based records. Hospital-based data [30, 32] usually reflect a small number of TB cases compared to those from the NTP database [14]. Moreover, hospitalbased studies often showed a higher rate of severe TB disease [33] and thus a lower proportion of treatment success. Two kinds of databases are useful to monitor the outcomes of TB, whether success or unsuccessful treatment $[9,33,34]$. The MyTB version 2.1 database includes a large number of variables, such as place of treatment, BCG scars, treatment regime, directly observed therapy (DOT) for the intensive phase, and DOT supervisor. However, this database needs improvement regarding the documentation of household income because there are many missing values. Nevertheless, nine independent variables were selected as determinants of treatment success among children in Malaysia.

The age of children independently determines their likelihood of treatment success when the analysis 
Table 2 Descriptive analysis of children with TB in Malaysia, 2013-2017

\begin{tabular}{|c|c|c|}
\hline Parameters & $\mathrm{n}$ & (\%) \\
\hline \multicolumn{3}{|l|}{ Socio-demographic profiles } \\
\hline Age (median, IQR) (n: 3317) & $8.5(10.5)$ & - \\
\hline \multicolumn{3}{|l|}{ Age groups } \\
\hline $0-4$ & 1313 & 37.0 \\
\hline $5-9$ & 691 & 19.5 \\
\hline $10-14$ & 1546 & 43.5 \\
\hline \multicolumn{3}{|l|}{ Sex } \\
\hline Male & 1726 & 48.6 \\
\hline Female & 1824 & 51.4 \\
\hline \multicolumn{3}{|l|}{ Citizenship } \\
\hline Malaysian & 3071 & 86.5 \\
\hline Non-Malaysian & 479 & 13.5 \\
\hline \multicolumn{3}{|l|}{ Ethnicity (n: 3546) } \\
\hline Malay & 1508 & 42.5 \\
\hline Chinese & 192 & 5.4 \\
\hline Indian & 127 & 3.6 \\
\hline Bumiputera Sabah & 703 & 19.8 \\
\hline Bumiputera Sarawak & 381 & 10.7 \\
\hline Others (Malaysian) & 156 & 4.4 \\
\hline Non-Malaysian & 479 & 13.5 \\
\hline \multicolumn{3}{|l|}{ Place of residence (n: 3516$)$} \\
\hline Urban & 1801 & 51.2 \\
\hline Rural & 1715 & 48.8 \\
\hline \multicolumn{3}{|l|}{ Health utilization } \\
\hline \multicolumn{3}{|l|}{ Treatment centre one } \\
\hline Public hospital & 2802 & 78.9 \\
\hline Public clinic & 579 & 16.3 \\
\hline Private facilities & 169 & 4.8 \\
\hline \multicolumn{3}{|l|}{ TB disease profiles } \\
\hline \multicolumn{3}{|l|}{ Category of cases } \\
\hline New case & 3461 & 97.5 \\
\hline Re-treatment & 89 & 2.5 \\
\hline \multicolumn{3}{|l|}{ Method of detection } \\
\hline Passive & 2827 & 79.6 \\
\hline Active & 723 & 20.4 \\
\hline \multicolumn{3}{|l|}{ BCG scar } \\
\hline Yes & 3072 & 86.5 \\
\hline No & 478 & 13.5 \\
\hline \multicolumn{3}{|l|}{ CXR finding (n: 3380) } \\
\hline No lesion & 895 & 26.5 \\
\hline Minimal & 1741 & 51.5 \\
\hline Advanced & 744 & 22.0 \\
\hline HIV co-infection & & \\
\hline
\end{tabular}

Table 2 Descriptive analysis of children with TB in Malaysia, 2013-2017 (Continued)

\begin{tabular}{lll}
\hline Parameters & $\mathbf{n}$ & (\%) \\
\hline Yes & 48 & 1.4 \\
No & 3502 & 98.6 \\
TB disease profiles & & \\
TB disease diagnosis & & 45.2 \\
$\quad$ aPTB sputum -ve & 1606 & 27.5 \\
PTB sputum +ve & 976 & 27.3 \\
EPTB & 968 & \\
TB meningitis & & 4.3 \\
Yes & 153 & 95.7 \\
No & 3397 & 1.9 \\
TB miliary & & 98.1 \\
Yes & 67 & \\
No & 3483 & 23.8 \\
Treatment outcomes & & 66.3 \\
Cured & 844 & 3.6 \\
Completed & 2353 & 0.1 \\
Death & 127 & 1.8 \\
Failed treatment & 4 & \\
Lost to follow up & 65 & \\
Not evaluated & 157 & cases) \\
\hline The PTB sputum -ve group, included PTB sputum not done (89 &
\end{tabular}

includes a continuous variable. The findings differed from previous studies in which the analysis employed a categorical variable $[9,14]$. However, the conclusions of this study and other studies were similar in that the older age group had a higher likelihood of treatment success than the 0-4-year age group [14, 35]. In this study, the categorical variable of age exhibited a significant interaction with other determinants, such as TB disease diagnosis and BCG scars, which led to biased estimates.

In terms of citizenship as a determinant of treatment success, Malaysian citizens had a higher likelihood of treatment success than non-Malaysians. This finding was in line with the national TB policy stating that TB treatment is free of charge. TB treatment in Malaysia utilizes a holistic approach including case detection, a DOT programme and TB counselling, effective followup and a BCG vaccination policy for newborns [5]. On the other hand, the non-Malaysian group included children from countries with a high TB burden and low BCG coverage. Although TB treatment is free in Malaysia, the initial evaluation procedure before the confirmation of TB disease is expensive. The associated financial burden may prevent non-Malaysian families from visiting the clinic at an early stage of health changes. 
Table 3 Treatment outcomes among children with TB in Malaysia, 2013-2017

\begin{tabular}{|c|c|c|c|c|c|}
\hline \multirow[t]{2}{*}{ Parameters } & \multicolumn{2}{|c|}{${ }^{\mathrm{a}}$ Successful } & \multicolumn{2}{|c|}{ bUnsuccessful } & \multirow[t]{2}{*}{$P$-value } \\
\hline & $\mathrm{n}$ & $\%$ & $\mathrm{n}$ & $\%$ & \\
\hline Overall & 3197 & 90.1 & 353 & 9.9 & - \\
\hline \multicolumn{6}{|c|}{ Socio-demographic profiles } \\
\hline Age (median, IQR) & \multicolumn{2}{|c|}{$8.9(10.6)$} & \multicolumn{2}{|c|}{$5.0(11.1)$} & $<0.001$ \\
\hline \multicolumn{6}{|l|}{ Age groups (years) } \\
\hline $0-4$ & 1131 & 86.1 & 182 & 13.9 & \\
\hline $5-9$ & 636 & 92.0 & 55 & 8.0 & \\
\hline $10-14$ & 1430 & 92.5 & 116 & 7.5 & $<0.001$ \\
\hline \multicolumn{6}{|l|}{ Sex } \\
\hline Male & 1538 & 89.1 & 188 & 10.9 & \\
\hline Female & 1659 & 91.0 & 165 & 9.0 & 0.075 \\
\hline \multicolumn{6}{|l|}{ Citizenship } \\
\hline Malaysian & 2857 & 93.0 & 214 & 7.0 & \\
\hline Non-Malaysian & 340 & 71.0 & 139 & 29.0 & $<0.001$ \\
\hline \multicolumn{6}{|l|}{ Place of residence } \\
\hline Urban & 1632 & 90.6 & 169 & 9.4 & \\
\hline Rural & 1534 & 89.4 & 181 & 10.6 & 0.270 \\
\hline \multicolumn{6}{|l|}{ Health utilization } \\
\hline \multicolumn{6}{|c|}{ Treatment centre one } \\
\hline Public hospital & 2489 & 88.8 & 313 & 11.2 & \\
\hline Public clinic & 549 & 94.8 & 30 & 5.2 & \\
\hline Private facilities & 159 & 94.1 & 10 & 5.9 & $<0.001$ \\
\hline \multicolumn{6}{|l|}{ TB disease profile } \\
\hline \multicolumn{6}{|c|}{ Method of detection } \\
\hline Passive & 2524 & 89.3 & 303 & 10.7 & \\
\hline Active & 673 & 93.1 & 50 & 6.9 & 0.003 \\
\hline \multicolumn{6}{|l|}{ BCG scar } \\
\hline Yes & 2850 & 92.8 & 222 & 7.2 & \\
\hline No & 347 & 72.6 & 131 & 27.4 & $<0.001$ \\
\hline \multicolumn{6}{|l|}{ CXR finding } \\
\hline No lesion & 819 & 91.5 & 76 & 8.5 & \\
\hline Minimal & 1607 & 92.3 & 134 & 7.7 & \\
\hline Advanced & 620 & 83.3 & 124 & 16.7 & $<0.001$ \\
\hline \multicolumn{6}{|l|}{ HIV co-infection } \\
\hline Yes & 35 & 72.9 & 13 & 27.1 & \\
\hline No & 3162 & 90.3 & 340 & 9.7 & $<0.001$ \\
\hline \multicolumn{6}{|l|}{ TB diagnosis } \\
\hline PTB SS -ve & 1473 & 91.7 & 133 & 8.3 & \\
\hline PTB SS + ve & 859 & 88.0 & 117 & 12.0 & \\
\hline EPTB & 865 & 89.4 & 103 & 10.6 & 0.007 \\
\hline
\end{tabular}

${ }^{\mathrm{a}}$ successful: the group of cured and completed

bunsuccessful: the group of failed, died, lost to follow up, not evaluated
TB was diagnosed in children in Malaysia primarily by sputum-negative PTB, followed by sputum-positive PTB and EPTB. The pattern of TB diagnosis among children was similar to that in previous studies [9, 14]. Studies from hospital-based settings report a higher percentage of EPTB than PTB and a higher number of more severe TB types, such as TB meningitis [33, 36]. Younger age groups have difficulty producing sputum samples; hence, sputum examination results rarely become positive for younger groups compared with older age groups [37]. Children with sputum-positive PTB and EPTB have a low likelihood of treatment success; in fact, children in EPTB groups may present with TB meningitis, a severe type of TB disease [33]. Children with sputum-positive PTB presented with a higher load of Mtb in their bodies, which triggered an excessive immune reaction that contributed to the probability of unsuccessful treatment among adolescents $[9,14,29]$. In addition, chest X-ray findings were associated with treatment success; children with chest X-ray results of advanced lesion were observed to have a low success rate compared with the rate for children whose chest X-ray showed no lesion or minimal lesion. Previous studies conducted in Ethiopia and Pakistan excluded chest X-ray results due to the availability of variables in their NTP database $[9,12,14]$. Recent local studies found an association of chest X-ray findings with unfavourable outcomes; however, these studies were conducted among all age groups [38, 39].

TB disease is associated with HIV co-infection because HIV alters the human immune system. HIV co-infection accounted for only $1.4 \%$ of the total TB cases among children in this study. Malaysia still has a low occurrence of HIV co-infection, but those who had HIV co-infection had low odds for TB treatment success. This finding was similar to the observations in other countries with a higher prevalence of HIV coinfection [14, 30, 35].

BCG vaccination provides protection from TB meningitis and miliary TB among the age group $0-4$ years and some protection from PTB until the age of 14 years [40]. Considering this fact, $86.5 \%$ of our registered TB cases among children had BCG scars. Children without BCG scars were more likely to be non-Malaysian citizens (304/479, 63.5\%) than Malaysian citizens (174/3071, 5.7\%). Children with BCG scars had a higher likelihood of treatment success than those without BCG scars in this study, possibly because they have been protected from severe TB. However, previous research in China did not find a significant association between BCG scars and TB treatment success with the utilization of hospital databases [33]. Many other studies in Ethiopia and Pakistan did not include the presence of BCG scars as a determinant of treatment success due to data availability in their NTP system $[9,12,14,35]$. 
Table 4 Multivariable logistic regression for the determinants of treatment success among children with TB in Malaysia, 2013-2017

\begin{tabular}{|c|c|c|c|c|c|c|c|c|c|c|c|}
\hline \multirow[t]{2}{*}{ Parameters } & \multirow{2}{*}{$\begin{array}{l}\text { Crude } \\
\text { OR }\end{array}$} & \multicolumn{2}{|l|}{$95 \% \mathrm{Cl}$} & \multirow{2}{*}{$\begin{array}{l}\text { Model } \\
1 \\
\text { aOR }\end{array}$} & \multicolumn{2}{|l|}{$95 \% \mathrm{Cl}$} & \multirow[t]{2}{*}{ P-value } & \multirow{2}{*}{$\begin{array}{l}\text { Model } \\
2^{\mathrm{a}} \mathrm{aOOR} \\
\text { (MICE) }\end{array}$} & \multicolumn{2}{|l|}{$95 \% \mathrm{Cl}$} & \multirow[t]{2}{*}{$P$-value } \\
\hline & & Lower & Upper & & Lower & Upper & & & Lower & Upper & \\
\hline \multicolumn{12}{|c|}{ Socio-demographic profiles } \\
\hline Age & 1.06 & 1.04 & 1.09 & 1.05 & 1.03 & 1.08 & $<0.001$ & 1.06 & 1.03 & 1.09 & $<0.001$ \\
\hline \multicolumn{12}{|l|}{ Sex } \\
\hline Male & ref & - & - & - & - & - & - & - & - & - & - \\
\hline Female & 1.23 & 0.99 & 1.53 & 1.00 & 0.77 & 1.30 & 0.987 & 1.11 & 0.88 & 1.41 & 0.384 \\
\hline \multicolumn{12}{|l|}{ Citizenship } \\
\hline Malaysian & 5.39 & 4.23 & 6.85 & 4.21 & 2.89 & 6.11 & $<0.001$ & 3.43 & 2.47 & 4.75 & $<0.001$ \\
\hline Non-Malaysian & ref & - & - & ref & - & - & - & ref & - & - & - \\
\hline \multicolumn{12}{|l|}{ Place of residence } \\
\hline Urban & 1.14 & 0.91 & 1.42 & 0.91 & 0.70 & 1.18 & 0.485 & 0.93 & 0.73 & 1.19 & 0.563 \\
\hline Rural & ref & - & - & - & - & - & - & - & - & - & - \\
\hline \multicolumn{12}{|c|}{ Treatment centre one } \\
\hline Public hospital & 0.43 & 0.29 & 0.63 & 0.37 & 0.21 & 0.61 & $<0.001$ & 0.38 & 0.25 & 0.58 & $<0.001$ \\
\hline Public clinic & ref & - & - & - & - & - & - & ref & - & - & - \\
\hline Private facilities & 0.87 & 0.43 & 1.91 & 0.78 & 0.34 & 1.94 & 0.581 & 0.79 & 0.36 & 1.71 & 0.544 \\
\hline \multicolumn{12}{|l|}{ TB disease profile } \\
\hline \multicolumn{12}{|l|}{ BCG scar } \\
\hline Yes & 4.85 & 3.8 & 6.17 & 1.88 & 1.28 & 2.72 & 0.00102 & 1.93 & 1.39 & 2.68 & $<0.001$ \\
\hline No & ref & - & - & ref & - & - & & ref & - & - & \\
\hline \multicolumn{12}{|l|}{ CXR finding } \\
\hline No lesion & ref & - & - & ref & - & - & & ref & - & - & \\
\hline Minimal & 1.11 & 0.83 & 1.49 & 0.97 & 0.66 & 1.41 & 0.868 & 1.01 & 0.70 & 1.44 & 0.976 \\
\hline Advanced & 0.46 & 0.34 & 0.63 & 0.48 & 0.32 & 0.71 & $<0.001$ & 0.48 & 0.33 & 0.69 & $<0.001$ \\
\hline \multicolumn{12}{|l|}{ HIV co-infection } \\
\hline Yes & 0.29 & 0.16 & 0.57 & 0.27 & 0.13 & 0.58 & $<0.001$ & 0.31 & 0.16 & 0.63 & 0.001 \\
\hline No & ref & - & - & ref & - & - & & ref & - & - & \\
\hline \multicolumn{12}{|l|}{ Type of TB } \\
\hline PTB SS -ve & ref & - & - & ref & - & - & & ref & - & - & \\
\hline PTB SS + ve & 0.66 & 0.51 & 0.86 & 0.62 & 0.44 & 0.86 & 0.004 & 0.58 & 0.43 & 0.79 & $<0.001$ \\
\hline ЕРТВ & 0.76 & 0.58 & 0.99 & 0.55 & 0.38 & 0.80 & 0.002 & 0.58 & 0.41 & 0.82 & 0.002 \\
\hline
\end{tabular}

Summary of model fit for Model 1:

Hosmer-Lemeshow goodness of fit: $p$-value $=0.1108$

Likelihood ratio test: $p$-value $<0.001$

Classification table: $90.6 \%$

Area under the curve: 0.73 (95\% Cl: 0.70-0.77)

Akaike information criterion: 1729.1

a aOR MICE: Adjusted odds ratio with multivariate imputation by chained equations

Place of treatment was another predictor of TB treatment success Children who were treated at a public hospital were less likely to succeed than those treated in a public clinic. Thus, cases in the hospital were more severe and difficult to manage. A local study using a Malaysian cohort in 2012 observed that a patient treated in a public hospital or clinic had a higher likelihood of unfavourable outcomes than those treated in a private facility; however, that study included all age groups [38].
Studies conducted in countries with a high TB burden did not include the place of treatment in their model; hence, comparisons cannot be made. Health facilities providing TB treatment should ensure that their services are patient-friendly to promote treatment success. In addition, early detection during active case evaluation, especially among younger age groups, may reduce the number of severe $\mathrm{TB}$ cases that require hospital management. 
The place of residence for children showed a nonsignificant result in the final model. Thus, the country's health services did not differ in terms of the accessibility and quality of TB care between urban and rural areas. A study conducted in Pakistan, with a high TB burden, observed that children from a rural area had higher odds of unsuccessful treatment [9], possibly because children in urban areas have greater access to health facilities, are better educated and are more confident taking modern medicine.

Among the socio-demographic determinants of treatment success or unsuccessful treatment outcomes, no association with children's sex was found in previous studies $[9,11]$. Similar findings were reported in our research, concluding that $\mathrm{TB}$ treatment success among children did not differ by sex.

\section{Limitations and strength of the study}

The study used secondary data that depended upon the availability of relevant parameters. A few variables could not be included because of the large amount of missing data and lack of valid definitions, such as those for household income, number of household dependents and education level. Thus, many predictors, such as economic status, parental education level and BMI status of the child, cannot be assessed in this study. Second, this study used a cross-sectional design; therefore, a causal relationship between the dependent and independent variables could not be established. The main strength of this study was the utilization of 5 years of data on TB case registration among children in Malaysia. The sample size in this research was adequate to generate statistically meaningful findings. Although secondary data analysis might have led to more missing values, only $1.6 \%$ of the values in the selected dataset were missing. The use of secondary data depends upon the percentage of missing data and the standard definition in the manual.

\section{Conclusions}

The overall rate of treatment success among children with TB in Malaysia has achieved the target of $90 \%$, except for children under 5 years of age. Treatment success among children with TB in Malaysia is positively associated with being a Malaysian citizen, being an older child and having BCG scars. Having HIV co-infection, being treated in public hospitals, having chest X-ray findings of advanced lesion, having sputum-positive PTB, and having EPTB were negatively associated with TB treatment success. Strategies for improving rates of treatment success include strengthening contact tracing activities and early identification among specific groups, such as the youngest and non-Malaysian groups.

\section{Abbreviations}

aOR: Adjusted odds ratios; BCG: Bacillus Calmette-Guérin; CAR: Companion to applied regression; CXR: Chest X-ray; DOT: Directly observed treatment; EPTB: Extrapulmonary tuberculosis; GLM: Generalized linear model; HIV: Human immunodeficiency virus; IQR: Interquartile range; MDR: Multidrug-resistant; MICE: Multivariate imputation by chained equations; Mtb: Mycobacterium tuberculosis; MyTB: Malaysian Tuberculosis Database; NTP: National Tuberculosis Control Programme; PTB: Pulmonary tuberculosis; TB: Tuberculosis; TBIS: Tuberculosis Information System; WHO: World Health Organization

\section{Acknowledgements \\ The author(s) would like to thank the Director-General of Health Malaysia for his permission to publish this article. We would also like to thank the Director of the Disease Control Division, Ministry of Health Malaysia, for permitting ac- cess to MyTB version 2.1.}

\section{Authors' contributions}

SMA, NI, SMY, YZ, NAL and MHM contributed to the design of the study, data cleaning, data analysis, interpretation of the findings and drafting of the manuscript. Finally, the manuscript was reviewed and critiqued by AR, FK, KIM and TA. The final version was approved by all the authors.

\section{Funding}

This survey was self-funded by the principal investigator, and the Universiti Teknologi MARA provided funding for the publication fee.

\section{Availability of data and materials}

The dataset of MyTB version 2.1 for 2013-2017 is available; anyone requesting this dataset should consult the TB Sector in the Ministry of Health, Malaysia.

\section{Ethics approval and consent to participate}

The study obtained approval from the Medical Research and Ethics Committee, Ministry of Health, with registration number NMRR-19-120147959, and was approved by the Research Ethics Committee Universiti Teknologi MARA (REC/617/19). This study involved secondary data analysis; thus, respondents' consent was not required. Nonetheless, a formal request to utilize data from the Disease Control Division, Ministry of Health Malaysia, was sought before initiating the study. All registered TB cases were made anonymous and given a unique new research identifier.

\section{Consent for publication}

Not applicable.

\section{Competing interests}

All authors disclose that they have no competing interests and no potential conflicts of interest regarding the publication of this article.

\section{Author details}

${ }^{1}$ Department of Public Health Medicine, Faculty of Medicine, Universiti Teknologi MARA, Sungai Buloh Campus, Jalan Hospital, 47000 Sungai Buloh, Selangor, Malaysia. ${ }^{2}$ Institute for Public Health, National Institutes of Health, Ministry of Health Malaysia, Setia Alam, Malaysia. ${ }^{3}$ Department of

Pharmaceutical Life Sciences, Faculty of Pharmacy, Universiti Teknologi MARA, Puncak Alam, Selangor, Malaysia. ${ }^{4}$ Sector of TB/Leprosy, Disease Control Division, Ministry of Health Malaysia, Putrajaya, Malaysia. ${ }^{5}$ Department of Community Medicine, School of Medical Sciences, Universiti Sains Malaysia, Kubang Kerian, Malaysia. ${ }^{6}$ Selangor Health State Department, Ministry of Health Malaysia, Shah Alam, Malaysia. ${ }^{7}$ Institute for Medical Research, National Institutes of Health, Ministry of Health Malaysia, Setia Alam, Malaysia.

Received: 5 February 2020 Accepted: 3 December 2020

Published online: 10 December 2020

\section{References}

1. Jenkins HE. Global burden of childhood tuberculosis. Pneumonia. 2016;8(1): 24 [cited 2019 Jan 8] Available from: http://pneumonia.biomedcentral.com/ articles/10.1186/s41479-016-0018-6. 
2. World Health Organization. Roadmap towards ending TB in children and adolescents, second edition. Geneva: World Health Organization; 2018.

3. Seddon JA, Shingadia D. Epidemiology and disease burden of tuberculosis in children: a global perspective. Infect Drug Resist. 2014;7:153-65.

4. World Health Organization. Global Tuberculosis Report 2019. Geneva; 2019. [cited 2019 Nov 12]. Available from: https://www.who.int/tb/global-report-2019.

5. Ministry of Health Malaysia. National Strategic Plan For Tuberculosis Control (2016-2020). Putrajaya: Ministry of Health Malaysia; 2016.

6. WHO | Tuberculosis country profiles. WHO. [cited 2019 Dec 12]. Available from: http://www.who.int/tb/country/data/profiles/en/.

7. Dodd PJ, Yuen CM, Sismanidis C, Seddon JA, Jenkins HE. The global burden of tuberculosis mortality in children: a mathematical modelling study. Lancet Glob Health. 2017;5(9):e898-906.

8. Stop TB Partnership. The Paradigm Shift 2016-2020: Global plan to end TB. Geneva, Switzerland: Stop TB Partnership; 2015; 2015.

9. Laghari M, Sulaiman SAS, Khan AH, Memon N. Epidemiology of tuberculosis and treatment outcomes among children in Pakistan: a 5 year retrospective study. PeerJ. 2018;6:e5253.

10. Ramos JM, Pérez-Butragueño M, Tesfamariam A, Reyes F, Tiziano G, Endirays J, et al. Comparing tuberculosis in children aged under 5 versus 5 to 14 years old in a rural hospital in southern Ethiopia: an 18-year retrospective cross-sectional study. BMC Public Health. 2019;19(1):856.

11. Alavi SM, Salmanzadeh S, Bakhtiyariniya P, Albagi A, Hemmatnia F, Alavi L. Prevalence and treatment outcome of pulmonary and extrapulmonary pediatric tuberculosis in southwestern Iran. Casp J Intern Med. 2015;6(4):213.

12. Dangisso MH, Datiko DG, Lindtjørn B. Low case notification rates of childhood tuberculosis in southern Ethiopia. BMC Pediatr. 2015;15(1):142

13. Wobudeya E, Sekadde-Kasirye M, Kimuli D, Mugabe F, Lukoye D. Trend and outcome of notified children with tuberculosis during 2011-2015 in Kampala, Uganda. BMC Public Health. 2017;17:963 [cited 2019 Mar 5] Available from: https://www.ncbi.nlm.nih.gov/pmc/articles/PMC5735639/.

14. Hailu D, Abegaz WE, Belay M. Childhood tuberculosis and its treatment outcomes in Addis Ababa: a 5-years retrospective study. BMC Pediatr. 2014; 14(1):61 [cited 2018 Dec 31] Available from: http://bmcpediatr. biomedcentral.com/articles/10.1186/1471-2431-14-61.

15. Donnan EJ, Coulter C, Simpson G, Clark J, Nourse C. Paediatric tuberculosis in Queensland, Australia: overrepresentation of cross-border and indigenous children. Int J Tuberc Lung Dis. 2017;21(3):263-9.

16. Mor Z, Cedar N, Pinsker G, Bibi H, Grotto I. Childhood tuberculosis in Israel: epidemiological trends and treatment outcomes, 1999-2010. Eur Respir J. 2013;41(5):1157-62.

17. World Health Organization. Definitions and reporting framework for tuberculosis-2013 revision. Geneva: World Health Organization; 2013. Report No.: 924150534.

18. Department of Statistics Malaysia Official Portal. [cited 2020 Jul 7]. Available from: https://www.dosm.gov.my/v1/index.php?r=column/cone\&menu_id= bDA2VkxRSU40STcxdkZ4OGJ0c1ZVdz09.

19. R Core Team. R: a language and environment for statistical computing. Vienna, Austria: R Foundation for statistical Computing; 2019. Available from: https://www.R-project.org/.

20. Dominic Comtois. summarytools: Tools to Quickly and Neatly Summarize Data. R package version 0.9.4. 2019. Available from: https://CRAN.R-project. org $/$ package $=$ summarytools.

21. Fox J, Weisberg S. An $\{R\}$ companion to applied regression [internet]. Third. Thousand Oaks: Sage; 2019. Available from: https://socialsciences.mcmaster. ca/jfox/Books/Companion/.

22. Subhash R. Lele, Jonah L. Keim, Peter Solymos. ResourceSelection: Resource Selection (Probability) Functions for Use-Availability Data. R package version 0.3-5. 2019. Available from: https://CRAN.R-project.org/package= ResourceSelection.

23. Hosmer DW Jr, Lemeshow S, Sturdivant RX. Applied logistic regression. 3rd ed. United States of America: Wiley; 2013.

24. van Buuren S, Groothuis-Oudshoor K. mice: Multivariate Imputation by Chained Equations in R. J Stat Software. 2011;45(3):1-67.

25. Basu Roy R, Whittaker E, Seddon JA, Kampmann B. Tuberculosis susceptibility and protection in children. Lancet Infect Dis. 2019;19(3): e96-108.

26. Galli L, Lancella L, Tersigni C, Venturini E, Chiappini E, Bergamini B, et al. Pediatric tuberculosis in Italian children: epidemiological and clinical data from the Italian register of pediatric tuberculosis. Int J Mol Sci. 2016;17(6):960.
27. World Health Organization. Standards and benchmarks for tuberculosis surveillance and vital registration systems: checklist and user guide. Geneva: World Health Organization; 2014. Report No.: 9241506725.

28. Marais BJ, Gie RP, Schaaf HS, Hesseling AC, Obihara CC, Starke JJ, et al. The natural history of childhood intra-thoracic tuberculosis: a critical review of literature from the pre-chemotherapy era; 2004. p. 11.

29. Vanden Driessche K, Persson A, Marais BJ, Fink PJ, Urdahl KB. Immune vulnerability of infants to tuberculosis. Clin Dev Immunol. 2013;2013:1-16.

30. Tilahun G, Gebre-Selassie S. Treatment outcomes of childhood tuberculosis in Addis Ababa: a five-year retrospective analysis. BMC Public Health. 2016; 16(1):612 [cited 2019 Feb 23] Available from: http://bmcpublichealth. biomedcentral.com/articles/10.1186/s12889-016-3193-8.

31. Yang C, Yasseen AS, Stimec J, Rea E, Waters V, Lam R, et al. Prevalence of tuberculosis infection and disease in children referred for tuberculosis medical surveillance in Ontario: a single-cohort study. CMAJ Open. 2018; 6(3):E365-71.

32. Kebede ZT, Taye BW, Matebe YH. Childhood tuberculosis: management and treatment outcomes among children in Northwest Ethiopia: a crosssectional study. Pan Afr Med J. 2017;27:25 [cited 2019 Feb 1] Available from: https://www.ncbi.nlm.nih.gov/pmc/articles/PMC5516653/.

33. Wu X-R, Yin Q-Q, Jiao A-X, Xu B-P, Sun L, Jiao W-W, et al. Pediatric tuberculosis at Beijing children's hospital: 2002-2010. Pediatrics. 2012;130(6): e1433-40.

34. Aw B, Ade S, Hinderaker SG, Dlamini N, Takarinda KC, Chiaa K, et al. Childhood tuberculosis in Mauritania, 2010-2015: diagnosis and outcomes in Nouakchott and the rest of the country. Public Health Action. 2017;7(3): 199-205.

35. Ogbudebe CL, Adepoju V, Ekerete-Udofia C, Abu E, Egesemba G, Chukwueme N, et al. Childhood tuberculosis in Nigeria: disease presentation and treatment outcomes. Health Serv Insights. 2018;11 [cited 2019 Mar 31] Available from: https://www.ncbi.nlm.nih.gov/pmc/articles/PMC5826094/.

36. Aketi L, Kashongwe Z, Kinsiona C, Fueza SB, Kokolomami J, Bolie G, et al. Childhood Tuberculosis in a Sub-Saharan Tertiary Facility: Epidemiology and Factors Associated with Treatment Outcome. Mokrousov I, editor. PLoS One 2016;11(4):e0153914.

37. Roya-Pabon CL, Perez-Velez CM. Tuberculosis exposure, infection and disease in children: a systematic diagnostic approach. Pneumonia. 2016;8(1):23.

38. Liew SM, Khoo EM, Ho BK, Lee YK, Mimi O, Fazlina MY, et al. Tuberculosis in Malaysia: predictors of treatment outcomes in a national registry. Int J Tuberc Lung Dis. 2015;19(7):764-71.

39. Tok PSK, Liew SM, Wong LP, Razali A, Loganathan T, Chinna K, et al. Determinants of unsuccessful treatment outcomes and mortality among tuberculosis patients in Malaysia: A registry-based cohort study. Ehtesham HS, editor. PLoS One. 2020;15(4):e0231986.

40. de Gijsel D, von Reyn CF. A breath of fresh air: BCG prevents adult pulmonary tuberculosis. Int J Infect Dis. 2019;80:S6-8.

\section{Publisher's Note}

Springer Nature remains neutral with regard to jurisdictional claims in published maps and institutional affiliations.

Ready to submit your research? Choose BMC and benefit from:

- fast, convenient online submission

- thorough peer review by experienced researchers in your field

- rapid publication on acceptance

- support for research data, including large and complex data types

- gold Open Access which fosters wider collaboration and increased citations

- maximum visibility for your research: over $100 \mathrm{M}$ website views per year

At BMC, research is always in progress.

Learn more biomedcentral.com/submissions 